interesse público, pratica atos, da mais variada ordem, dispondo de determinados direitos patrimoniais, ainda que não possa fazê-lo em relação a outros deles. Por exemplo, não pode dispor dos direitos patrimoniais que detém sobre os bens públicos de uso comum.

Mas é certo que inúmeras vezes deve dispor de direitos patrimoniais, sem que com isso esteja a dispor do interesse público, porque a realização deste último é alcançada mediante a disposição daqueles.

Bem a propósito, as observações de ALESSI e de CELSO ANTÔNIO BANDEIRA DE MELLO, acima reproduzidas, permitem-nos salientar a circunstância de, v.g., realizar-se o interesse público na omissão, pela Administração, do uso de recursos judiciais meramente protelatórios, que se prestam unicamente a retardar, em beneficio exclusivo do interesse da Administração, secundário, o cumprimento de suas obrigações.

Daí porque, sempre que puder contratar, o que importa disponibilidade de direitos patrimoniais, poderá a Administração, sem que isso importe disposição do interesse público, convencionar cláusula de arbitragem. Retorno à esta altura, às observações de THEMISTOCLES CAVALCANTI para afirmar que precisamente o fazendo Administração estará a prestar acatamento ao interesse público.

O debate a respeito da juridicidade da solução, mediante arbitragem, de conflitos entre as partes nos "contratos administrativos" será, como se vê, facilmente espancado se um mínimo de reflexão vier a ser praticado em torno do núcleo da questão.

\title{
MERCOSUL: Problemática Factual e Institucional
}

\author{
Dr. Melio Gaguaribe de Mattos* \\ Instituto de Estudos Políticos e Sociais
}

\section{Problemas de Mercosul}

\section{Aspectos gerais}

Mercosul constituiu a culminação de um processo de aproximação e integração entre Argentina e Brasil, iniciado com o Acordo de Itaipú, firmado pelos presidentes Sarney e Alfonsín em 30-XI-1995. O Tratado de Assunção, que instituiu Mercosul, nele integrando Argentina, Brasil, Paraguai e Uruguai, foi firmado em 29-111-1991. Está Mercosul, assim, em vias de completar dez anos de funcionamento.

Nesse período, Mercosul se consolidou como um importante mercado sub-regional, que absorve apreciável parcela das exportações de Argentina e Brasil e mais de metade das dos dois outros partícipes. Consolidou-se, também como um importante protagonista internacional, proporcionando a seus membros um poder de negociação e uma audiência que, isoladamente nenhum poderia ter.
Sem embargo de seu saldo extremamente positivo, Mercosul acusa, em fim dos anos 90 alguns graves problemas, que podem ser agrupados em duas ordens de questões; as de caráter factual e as de caráter institucional.

Os problemas factuais se desdobram em um considerável número de itens. Alguns representam a inevitável reação, em todos os processos integrativos, de setores de um país membro que se revelam subcompetitivos, relativamente aos de outro país membro, do que são exemplos típicos o açúcar argentino, ante o brasileiro, e o trigo brasileiro, ante o argentino. Outros, mais complicados, decorrem de assimetrias estruturais, cuja correção pode exigir prazos mais longos ou complexas gestões institucionais.

As questões de ordem institucional decorrem do fato de que se observa uma crescente falta de correspondência entre o desenvolvimento econômico de Mercosul e sua precária estruturação institucional. Mercosul continua funcionando, para todos os efeitos,

* Helio Jaguaribe de Mattos - Graduou-se em direito na PUC/RJ e é PHD em Ciência Política pela Universidade de Mainz, na Alemanha. Foi professor e chefe do Departamento de Ciências do ISEB, ex-professor das Universidades de Harvard, Stanfor e do M.I.T. É décano, desde 1979, do Instituto de Estudos Políticos e Sociais - IEPES do Rio de Janeiro. Foi itular da pasta de Ciência e Tecnologia de abril a setembro de 1992. É autor de numerosa obra no campo do desenvolvimento politico e social, das relaçoes internacionais, dos estudos latino-americanos e da teoria social. 
na base do consenso entre seus partícipes, não dispondo de mecanismos próprios nem para sua auto-administração nem, mesmo, para dirimir controvérsias entre empresas dos países partícipes, as quais tendem a ocorrer com tanto mais freqüência quanto maior o volume de transações que se realizem. Padece Mercosul, assim, de efeitos fortemente paralizantes. Daí resulta, por um lado, uma crescente sobrecarga da agenda dos órgãos de cúpula dos países membros, os implicando em dirimir disputas interempresariais que deveriam ter distinto processamento. Por outro lado, a falta de satisfatória institucionalidade própria, dentro de um contexto factual caracterizado por fortes assimetrias, induz os interesses privados em jogo a buscar, nas autoridades judiciais de seus respectivos países, soluções que resultam incompatíveis com o Tratado de Assunção. É de salientar-se, a esse respeito, a preocupante medida em que autoridades judiciais de primeira instância vêm ignorando, em suas sentenças, as disposições do Tratado de Assunção que, de jure, se sobrepõem às legislações nacionais com elas eventualmente discrepantes.

\section{Questões factuais}

Como precedentemente mencionado, os processos de integração inevitavelmente implicam na necessidade, por parte de cada país membro, de abandonar seus setores subcompetitivos, em favor dos mais competitivos de outro país membro. O trigo brasileiro e o açúcar argentino são exemplos típicos dessa situação. É precisamente para ceder, em seu respectivo mercado nacional, espaço aos setores mais competitivos dos outros partícipes, que as integrações são concebidas, o que resulta em vantagens para todos, quando seja satisfatoriamente equilibrado o intercâmbio global.
O trigo gaúcho é vantajosamente substituído pelo argentino, cabendo aos produtores brasileiros se deslocarem para outros setores, como o da soja. O açúcar tucumenho é vantajosamente substituído pelo brasileiro, cabendo aos produtores argentinos se deslocarem para outros setores, como o de cítricos. Os países partícipes devem contribuir para que tais substituições se processem da melhor forma possível, estimulando e facilitando a reorientação dos produtores, em vez de tentar proteções incompatíveis com a letra e o espírito das normas integrativas.

A questão se torna mais dificil entretanto, quando o problema da deficiência de competitividade não dependa de especializações setoriais, para o favorecimento das quais, precisamente, se destina o processo integrativo, mas de fatores de ordem geral, que inibam o sistema produtivo de um país membro. Como foi contemplado pelos iniciadores de Mercosul, este se destina a optimizar a economia de cada partícipe. Se um determinado país membro se defronte com uma situação de generalizada subcompetitividade, o próprio sistema integrativo tem de ser revisto. Algo disto está presentemente se verificando nas relações entre Argentina e Brasil.

A esse respeito, entretanto, importa considerar dois distintos aspectos. Um deles se refere a certas importantes deficiências de que se ressente a capacidade exportadora da Argentina. O outro diz respeito ao fato de que, não obstante tais deficiências, a Argentina vem mantendo um saldo favorável em sua balança de comércio com o Brasil, o que significa que, globalmente, o intercâmbio com o Brasil lhe é favorável. Esta última circunstância desautoriza, na própria perspectiva da Argentina, as invocações antiMercosul formulada por alguns setores daquele país.
Isto não obstante, importa levar na devida conta importantes deficiências que afetam a capacidade exportadora da Argentina. Essas deficiências foram muito bem descritas e analisadas, entre outros autores, por Aldo Ferrer' ${ }^{1}$. Em última análise, tais deficiências resultam de duas diferentes ordens de fatores. Por um lado, ocorre, como salientado por Ferrer, que a Argentina seguiu, nos últimos vinte anos, por influência de um predominante neoliberalismo, uma política de desindustrialização, enquanto o Brasil, não obstante não ter ficado imune das pressões ideológicas da mesma natureza, manteve, ainda que menos dinamicamente que no passado, sua política de industrialização. Decorrentemente, a Argentina se encontra em condições subcompetitivas, relativamente a diversos setores industriais brasileiros (e mais ainda em termos internacionais) e fica demasiado restrita a exportações agropecuárias e de petróleo.

Por outro lado, o sistema de rígida paridade cambial com o dólar, que se revelou eficaz na supressão da hiperinflação argentina, vem se tornando crescentemente oneroso, na medida em que a efetiva desvalorização do peso não é cambialmente corrigida. Estima-se, atualmente, que essa desvalorização seja da ordem de $30 \%$, o que estrangula de um modo geral todas as exportações argentina, salvo as supercompetitivas e, por outro lado, estimula, desrazoavelmente, as importações.

\section{Aspecto institucional}

Como precedentemente mencionado, Mercosul, embora tenha adquirido personalidade jurídica, continua dependendo do consenso dos partícipes para todas as decisões coletivas, seja através do Conselho do Mercado Comum, seja por entendimentos de cúpula entre presidentes.

Em matéria institucional, comparativamente à União Européia, que dispõe de completo acervo de mecanismos supranacionais, Mercosul necessitaria criar, pelo menos, alguns de organismos supranacionais mais imediatamente necessários. Entre estes avulta a indispensabilidade de uma Secretaria mais autônoma, inclusive com apropriadas funções técnicas e uma instituição jurisdicional supranacional, para dirimir contendas civis e comerciais, reservando-se para a cúpula do sistema importantes assuntos políticos.

A carência de mecanismos supranacionais, em Mercosul, não decorre da falta de propósito integrativo, por parte dos partícipes, mas do fato de que, com sua presente composição, Mercosul carece de suficiente equilíbrio, entre os países membros. Com efeito, como o demonstra o quadro abaixo, o Brasil, relativamente às três mais importantes variáveis do grupo, detêm uma posição excessivamente majoritária. Se se a levar em conta, o voto brasileiro sempre ultrapassaria o conjunto do grupo. Se, diversamente, se ignorar o princípio da proporcionalidade, o Brasil se sentiria prejudicado. 
MERCOSUL

Principais Variáveis

\begin{tabular}{|l|c|c|c|c|c|}
\hline ITENS & ARGENTINA & BRASIL & PARAGUAI & URUGUAI & TOTAL \\
\hline $\begin{array}{l}\text { População } \\
\text { (milhões, 1998) }\end{array}$ & 31,1 & 166,3 & 5,2 & 3,3 & 205,9 \\
\hline $\begin{array}{l}\text { PIB US\$ } \\
\text { (bilhões, 1998) }\end{array}$ & 242 & 556 & 8 & 11 & 817 \\
\hline $\begin{array}{l}\text { Exportações } \\
\text { intra-Mercosul } \\
\text { (US\$ bilhões, 1998) }\end{array}$ & 4,5 & 8,9 & 0,3 & 1,3 & 15 \\
\hline $\begin{array}{l}\text { Brasil - por população } \\
\text { - por PIB } \\
\text { - por exportações }\end{array}$ & $\begin{array}{l}68,8 \% \\
59,3 \%\end{array}$ \\
\hline
\end{tabular}

A correção desse desequilíbrio depende, entre outras medidas, do alargamento de Mercosul, com o previsto ingresso de países como Bolívia, Chile e Venezuela.

Sem embargo de considerações de ordem mais geral, estão na agenda de Mercosul duas medidas que provavelmente serão adotadas a prazo relativamente curto. Uma consiste em se converter o atual regime de arbitragem em um sistema jurisdicional de caráter supranacional, para dirimir controvérsias privadas intra-Mercosul. A outra consiste em se reforçar as atribuições da atual Secretaria, se the conferindo, também, funções técnicas e se lhe dando mais ampla competência.

\section{O Cenário Internacional}

\section{Considerações prévias}

Uma apropriada discussão da problemática factual e institucional de Mercosul requer se tenha em vista o atual cenário

internacional e suas prováveis tendências evolutivas. Com efeito, ademais de estar, de múltiplas formas, economicamente inserido no sistema internacional, nele Mercosul é um protagonista político e dele depende, decisivamente, a margem de autonomia externa de que possam dispor seus participes.

O primeiro e principal fato a se levar em conta, relativamente ao atual sistema internacional, é a predominante posição que nele ocupam os Estados Unidos.

Os Estados Unidos, convertidos em única superpotência, depois da implosão da União Soviética, em 1991, se encontram numa situação muito especial que Samuel Huntington, ${ }^{2}$ acertadamente, designou de "unimultipolaridade". Tal situação resulta do fato de que condições internas e externas não permitem que a incontrastada supremacia mundial americana, em termos militares e econômico-tecnológicos, se constitua em uma igualmente incontrastável hegemonia mundial. Os Estados Unidos dispõem de uma hegemonia

${ }^{2}$ Cf. Sarnuel Huntington, "A Superpotência Solitária", in Política Externa Vol. 8, № 4 março-abril, maio, p. 12-25. Revista da Faculdade de Direito da UFRGS, v. 21, Março/2002 relativa, conducente a uma supremacia mundial submetida a condições restritivas de ordem doméstica e internacional. Ou seja, dispõem de um regime de relativa unipolaridade, cujo exercício é restringido, domesticamente, por constrangimentos político-institucionais e socioculturais e internacionalmente, ou multipolarmente, por resistências procedentes tanto de potências amigas como não amigas. Tais resistências se revelam eficazes na medida em que, dados os constrangimentos domésticos que restringern as margens de atuação unilateral dos Estados Unidos, estes não dispõem de condições nem para ignorar essas resistências nem para coercitivamente as suprimir.

Como democracia de massas os Estados Unidos são regulados por instituições não compatíveis com o exercício de um imperialismo ostensivo, que requer, de parte da metrópole imperial, um governo autoritário, como se verificou em todos os impérios históricos, do Assírio e Egípcio ao Romano, ao Império Espanhol, ao de Napoleão. É interessante observar como o Império Britânico, formado durante o período de uma democracia aristocrática de caráter autoritário, se tornou, sem prejuízo de outros fatores, crescentemente inviável a partir da segunda metade do século XIX, conforme o regime inglês evoluia para se tornar uma democracia de classe média, com Gladstone e se tornou impossível quando Inglaterra se converteu, com Attlee, em uma democracia social de massas.

Acrescente-se, no caso dos Estados Unidos, o fato de que o povo americano, embora se orgulhe de sua condição de única superpotência e pretenda preservá-la, não se dispõe, por outro lado, a sacrificios pessoais e financeiros para sustentar aventuras imperiais. Roma, em contrapartida, constituiu e manteve seu império, a partir de Mário, (108 AC), com legiões formadas por voluntários e deixou de subsistir quando mudanças de mentalidade e de estilos de vida, a partir do século IV AD, privaram de voluntários o recrutamento militar.
A elite de poder americana, depois do fracasso do Vietnã, motivado, precisamente pelas resistências domésticas a um ostensivo imperialismo, foi capaz de montar um sistema de guerra aeroespacial que se pode travar praticamente sem custos de vidas americanas e sem apelo ao recrutamento militar, como ficou demonstrado no caso da guerra do Golfo. Assim mesmo, entretanto, ações militares desse tipo requerem que elas se revistam, aos olhos do público americano e, de um modo geral, do mundo, de "legitimidade". Legitimidade que pode ser conferida, como no caso da guerra do Golfo, pelo Conselho de Segurança das Nações Unidas ou, mais precariamente, como no caso de Kosovo, pela OTAN. Em todos esses casos, entretanto, se faz mister a prévia "demonização" do inimigo, seja este Sadam Hussein ou Milosevic.

Potências amigas, como as da Europa e não tão amigas, como China, Rússia, Irã e outras, objetam a intervenções militares unilaterais, por parte dos Estados Unidos e exigem para tais intervenções expresso mandato das Nações Unidas ou, no caso dos europeus, pelo menos, da Aliança Atlântica. Daí o regime de "unimultipolaridade" referido por Huntington.

\section{Nova estratificação internacional}

O sistema internacional que se configurou sob o regime da unimultipolaridade americana tem características pouco estáveis. A mais longo prazo esse regime ou bem conduzirá a uma consolidação e generalização da hegemonia americana, gerando um efetivo unipolarismo, ou bem, diversamente, acentuará suas características multipolares, gerando uma ordem mundial algo semelhante à do século XIX. Um novo regime multipolar, entretanto, tenderá a se caracterizar pela constituição, formal ou informalmente, de um diretório mundial, compreendendo as grandes potências, provavelmente coincidindo com a formação de

Revista da Faculdade de Direito da UFRGS, v. 21, Março/2002 
um novo Conselho de Segurança operando, pelo menos de jure, sob a égide das Nações Unidas.

Presentemente, o instável regime de unimultipolaridade apresenta uma estratificação de poder mundial dividida em três níveis. Um nível dirigente, sob a supremacia dos Estados Unidos, incluindo, em menor grau de influência a União Européia - notadamente Alemanha França e Inglaterra e o Japão.

O segundo nível da presente estratificação mundial inclui países dotados de relativa autonomia doméstica e internacional, que não dispõem de condições de se oporem à supremacia americana mas podem oferecer-lhe suficiente resistência para preservarem apreciável margem de autonomia internacional e maior ainda de autonomia doméstica. Tais países são China, Rússia, Índia e Irã. O Brasi dispõe, potencialmente no âmbito de Mercosul, de acesso a esse nível.

O terceiro nível de estratificação internacional é um nível de dependência, que compreende o conjunto dos demais países. Um país como a Suiça, na medida em que se alinhe com a União Européia e atue em consonância com esta, ainda que dela não fazendo formalmente pane, participa do nível de relativa autonomia. Isoladamente, a Suíça resvala para o nível de dependência.

A instabilidade própria à presente condição americana de unimultipolaridade $s$ faz sentir em todos os três níveis de estratificação mundial do poder. Um país como a China, se mantiver por alguns decênios sua presente unidade interna e sua acelerada taxa de desenvolvimento econômico, tenderá, em meados do século entrante, a atingir condições de eqüipolência como os Estados Unidos Diversamente, se tal não ocorrer, a China será submetida a terríveis processos disruptivos, tendentes a sua fragmentação interna. Rússia de forma equivalente, dispõe de um par de

decênios para recuperar sua condição de superpotência, ou sofrer fortíssimos processos disruptivos, também a ameaçando de fragmentação. Índia e Irã estão, igualmente, submetidos a alternativa de consolidarem seu desenvolvimento e sua unidade interna, com possível acesso ao nível dirigente, ou serem submetidos a gravíssimos processos disruptivos, resvalando para o nível de dependência.

Um país de grande população, como o Brasil, que presentemente se situa entre o nível de relativa autonomia e o nível de dependência, ostenta uma situação particularmente instável. Se o Brasil lograr, dentro de um par de decênios e no âmbito de Mercosul, superar seu renitente subdesenvolvimento, tenderá a consolidar sua posição no nível de relativa autonomia, com possibilidades de futuro progresso. Se, diversamente, mantiver seu presente subdesenvolvimento e perder a margem de autonomia de que ainda dispõe, sofrerá, como China e Rússia, terríveis processos disruptivos, com possível fragmentação de sua unidade nacional.

A instabilidade do presente sistema internacional tende a conduzi-lo, até meados do século entrante, a uma alternativa básica: consolidação da hegemonia americana, gerando um longo período de Pax Americana ou, diversamente, formação de um novo sistema multipolar, em que os Estados Unidos deverão, seguramente, exercer um papel relevante, mas em que tenderão a ser também relevantes países ou sistemas como China, Rússia, União Européia e alguns outros. As mais importantes variáveis, para o segundo cenário são, por um lado, o continuado desenvolvimento da China e, a superação, pela Rússia, de suas atuais condições caóticas e, por outro lado, a adoção, pela União Européia, de uma política externa e de defesa própria. Não dispondo os Estados Unidos de condições para a preventiva eliminação de rivais (China e Rússia) ou Revista da Faculdade de Direito da UFRGS, v. 21, Março/2002 preventivo controle da U.E., a tendência de que venha a prevalecer, em meados do século XXI, uma ordem mundial multipolar - em detrimento da Pax Americana depende, predominante, mas não exclusivamente, de um exitoso desenvolvimento chinês.

\section{O processo de globalização}

Como tem sido salientado por Aldo Ferrer $^{3} \mathrm{o}$ atual processo de globalização constitui a terceira onda, incomparavelmente mais ampla e profunda, de um processo que se iniciou com as descobertas marítimas e o subsequente mercantilismo, prosseguiu, em maior escala, com a revolução industrial e atingiu, nas últimas décadas do século $\mathrm{XX}$, imensas e planetárias proporções com a revolução tecnológica.

As principais características da terceira onda desse processo consistem, a partir da prática instantaneidade das comunicações internacionais e das facilidades para rápido e pouco dispendioso transporte internacional, no predomínio das técnicas informacionais no processo produtivo, na livre e imediata movimentação telemática de bilhões de dólares de um mercado a outro, assim como na descentralização geográfica dos processios produtivos e gestionários.

Como ocorreu com as precedentes ondas do processo de globalização, a atual é fortemente concentradora nas relações centroperiférica. As grandes civilizações orientais, como Índia e China, ostentavam, na era dos descobrimentos marítimos, um nível civilizatório algo superior ao ocidental. Isto não obstante, a

revolução mercantil, assegurando aos europeus superioridade na navegação de longo curso e nos processos de coordenação da oferta da produção artesanal, proporcionaram uma vantagem da ordem de 2 para 1 à economia ocidental. Essa vantagem se tornou da ordem de 10 para 1 com a Revolução Industrial. Com a presente revolução tecnológica ela assumiu proporções de 60 para 1

As empresas multinacionais americanas, acompanhadas por algumas européias e japonesas, dispõem de extraordinária superioridade sobre as empresas convencionais do resto do mundo. Essa superioridade reside em parte, na não compartida detenção de inovações tecnológicas. Em parte, na grande vantagem de economias de escala, com regimes mais eficientes de gestão, fácil acesso a amplíssimos mercados de capitais e a não menos amplas fontes de financiamento a baixo custo. E ainda consistem, de forma a lhes assegurar definitiva superioridade, na detenção de um regime privilegiado de comércio internacional. Como salientado por Luciano Coutinho e João Furtado ${ }^{5}$ principio de "livre comércio", tão veemente defendido pelos Estados Unidos e pelas teorias neoliberais, é completamente ultrapassado, na prática, pela rede das multinacionais. $\mathrm{Na}$ verdade, estamos ingressando numa era de fim de liberdade de comércio. Mais de 1/3 das exportações americanas e de $2 / 5$ de suas importações se processam por transações entre matrizes e filiais de multinacionais. Essas transações não decorrem de atendimento dos princípios de optimização da relação custo-qualidade e sim do interesse das empresas de reterem em sua

Cf. Aldo Ferrer, História de la Globalización, Vols. 1 e 2, México, Fondo de Cultura Económica, 1996 e 1999. Cf. Osvaldo Sunkei e Pedro Paz, El Subdesarrollo Latinoamericano v Ia Teoría dei Desarrollo, México, Siglo XXI, 1970 e atuais níveis a partir de dados comparativos do PIB.

${ }^{5}$ Cf. Luciano Coutinho e João Furtado, “A Integração Contincntal Assimétrica e Acelerada: Riscos e Oportunidades de ALCA" in Samuel Pinheiro Guimarães, Org., ALCA e Mercosul - Riscos e Oportunidades para o Brasil, Brasilia, IPRI, 1999 
rede suas próprias transações. Esta é uma das principais razões pelas quais o comércio internacional dos países periféricos fica restrito àexportação de "commodities", de baixo preço e demanda de reduzido crescimento.

$O$ resultado final do processo de globalização consiste na prática eliminação da soberania da maior parte dos países do mundo, reduzindo-os a segmentos anônimos do mercado internacional, exogenamente dirigidos pelas grandes multinacionais e potências com jurisdição sobre suas respectivas matrizes.

\section{Situação da América do Sul}

O continente sul-americano, com a pequena exceção de Guiana e Suriname, compreende dois grandes blocos sub-regionais: Mercosul e Pacto Andino. Mercosul, integrando, fonnalmente, Argentina, Brasil, Paraguai e Uruguai, constitui o principal sistema da região, contendo uma área territorial de mais de 11.862 mil km $^{2}$ uma população de mais de 200 milhões de habitantes e um PIB de mais de um trilhão de dólares. Bolivia e Chile, associados a Mercosul, detêm em conjunto uma população de cerca de 22 milhões de habitantes e um PIB de cerca de US\$80 bilhões. Do outro lado, os demais países do Pacto Andino, Colômbia, Equador e Peru, representam uma população de mais de 72 milhões de habitantes com um PIB somando cerca de US $\$ 170$ bilhões.

\section{Mercosul}

O comércio intra-regional de Mercosul absorve $25 \%$ das exportações de seus participes, mas é particularmente importante para todos. Para Paraguai e Uruguai representa, respectivamente, $61 \%$ e $55 \%$ de suas exportações totais. Para a Argentina, 36\%. Para o Brasil, $17 \%$, sendo de notar-se, entretanto, que Mercosul é o principal mercado para as exportações brasileiras de alto valor agregado.

A relevância de Mercosul para seus participes excede de muito, entretanto, sua significação como mercado sub-regional, por importante que esta seja. Com efeito, de um ponto de vista econômico, Mercosul, ademais de assegurar o escoamento de significativa, ou majoritária, parcela das exportações dos países integrantes, lhes proporciona um âmbito favorecido no interior do qual podem determinar, empírica e operacionalmente, quais são seus setores produtivos dotados de competitividade internacional ou aptos a adquiri-la, mediante exeqüíveis melhoramentos técnico-gerenciais. Mercosul, destarte, funciona como um campo protegido para a comprovação da competitividade internacional das exportações de seus membros e para o adestramento de seus setores mais aptos a se tornarem competitivos.

Mais do que o econômico, entretanto, avulta o papel de Mercosul como sistema de asseguramento da autonomia nacional de seus participes, no âmbito dos efeitos altamente desnacionalizantes produzidos pelo processo de globalização. Mercosul, por um lado, proporciona a seus membros um poder internacional de negociação que nenhum dos países que o integram, inclusive o Brasil, poderia isoladamente ter. Por ouro lado, Mercosul é o principal fator de preservação das margens de autonomia internacional de que ainda dispõem seus participes, os quais isoladamente, notadamente nos casos de Paraguai e Uruguai, tenderiam, a relativamente curto prazo, a se converter em segmentos anônimos do mercado internacional, exogenamente dirigidos pelas grandes multinacionais e potências com jurisdição sobre suas matrizes.

Não obstante sua alta taxa de êxito, Mercosul se defronta com dois importantes problemas. Por um lado, passado o "período áureo", de 1991 a 1995, Mercosul vem dando crescentes indicações de debilidades estruturais, devidas ao que Aldo Ferrer denomina de seus "quatro pecados capitais"6. Esses pecados afetam, particularmente, as duas grandes economias do sistema, Argentina e Brasil, e podem ser enumerados da seguinte forma: (1) excessiva dependência do mercado financeiro internacional; (2) deficiente integração social doméstica; (3) assimetria das estratégias nacionais e (4) divergências na inserção internacional.

Mercosul, por outro lado, constitui um sistema insuficientemente amplo para assegurar, satisfatoriamente, a mais longo prazo, os interesses internacionais de seus participes. Importaria, no que se refere ao próprio sistema, a ele incorporar alguns outros países sulamericanos, notadamente Chile e Bolívia, a ele já associados e Venezuela, que demonstra interesse em nele ingressar. Importaria, adicionalmente, ajustar com o Pacto Andino um sistema sul-americano de cooperação econômica e política, que gerasse no continente uma área de livre comércio para os respectivos países.

No que se refere aos "pecados capitais" assinalados por Aldo Ferrer importa indicar, muito brevemente, em que consistem os mesmos. A excessiva dependência do mercado financeiro internacional representa a principal limitação estrutural do eixo Argentina-Brasil. Em ambos os países sua balança comercial não gera suficiente saldos para arcar com seus débitos em transações internacionais, decorrente do serviço da dívida, remessa de lucros e outros itens. Daí resulta, para a Argentina, um déficit anual, em seu balanço de pagamentos, da ordem de US $\$ 15$ bilhões e, para o Brasil, da ordem de US $\$ 25$ bilhões. Para cobrir esses déficits ambos os países dependem do ingresso anual de capitais estrangeiros por não menores montantes, lhes gerando uma dependência estrutural do mercado financeiro internacional.

A margem de pobreza e de exclusão social, significativa no caso da Argentina, assume proporções alarmantes no caso do Brasil, afetando cerca de $30 \%$ de sua população. Enquanto não for corrigida essa grave deficiência, esses países, notadamente o Brasil, padecem de insuficiente margem de integração social, com decorrente debilitação de seu poder nacional.

Mais graves, a curto e médio prazos, são as duas outras limitações apontadas por Ferrer. No que se refere às assimetrias nas respectivas estratégicas nacionais, Ferrer mostra como graves inconsistências na orientação econômica da Argentina, nos últimos vinte anos, a levaram, por insensatas motivações ideológicas (caso típico de Martinez de $\mathrm{Hoz}$ ) a sacrificar seu parque industrial, convertendo 0 país num produtor de produtos agropastoris e de petróleo, enquanto o Brasil manteve e expandiu sua capacidade industrial. Daí importantes desequilíbrios qualitativos nas relações de troca entre Argentina e Brasil.

No que se refere à respectiva inserção internacional, Ferrer salienta o fato de que em ambos os países, mas notadamente no caso da Argentina, importantes setores da opinião pública e, decorrentemente, das forças políticas, aceitam os princípios neoliberais como indeclináveis normas econômicas. Como decorrência da aceitação passiva do jogo do mercado internacional e da renúncia a uma deliberada intervenção do Estado na promoção do desenvolvimento econômico e preservação de sua autonomia interna, o país fica à mercê das forças internacionais e perde capacidade decisória.
“"Cf. Aldo Ferrer "Argentina-Brasil, Mercosul e Integração Sul-Americana” in Política Externa, Vol. 9, N. 2, setembro, outubro, novembro, dezembro, pgs. 5-17.

Revista da Faculdade de Direito da UFRGS, v. 21, Março/2002 
A situação descrita por Ferrer se reveste de extrema gravidade. Como se discutirá subseqüentemente, Argentina e Brasil não dispõem, historicamente, para consolidar Mercosul, do tempo necessário para que, previamente, corrijam os "quatro pecados" mencionados por Ferrer, notadamente no que se refere àsuperação, necessariamente lenta, de seus coeficientes de pobreza e exclusão social. A consolidação de Mercosul constitui uma tarefa extremamente urgente e absolutamente indispensável para a sobrevivência naciona dos países membros. Importa assim, entre outras medidas, que Argentina e Brasil procedam, prontamente, a uma ampla discussão dos problemas com que se defronta seu relacionamento em Mercosul, independentemente do que estipulem os tratados e sim levando em conta a absoluta necessidade, para a sobrevivência de ambos, de encontrar um ajuste durável para o equilíbrio de suas transações. Mais do que um importante mercado sub-regional, Mercosul é para os participes seu passaporte para a história.

\section{Requisitos de Viabilidade}

\section{Aspecto geral}

$O$ quadro internacional precedente indicado, bem como o acelerado processo de globalização em marcha, com seus decorrentes efeitos, revelam, de forma irretorquível, absoluta necessidade de se manter, consolidar e expandir Mercosul. Mais do que um importante mercado comum, Mercosul é a condição necessária de possibilidade de sobrevivência histórica dos países que o integram.

Face a tal situação, os problemas com que presentemente se defronta Mercosul não podem ser tratados topicamente, ou meramente em função dos convênios em vigor, mas sim tendo em vista a possível optimização de Mercosul para todos os seus membros. Mercosul só poderá resistir às sérias pressões a que já está submetido e às, ainda mais graves, que decorrem do projeto americano de ALCA se, por um lado, sua relevância não apenas econômica mas política e histórica, for plenamente reconhecida por todos os países membros, incluído o imperativo, por parte de Mercosul, de se recusar à constituição de uma área de livre comércio nas Américas, como propõe o projeto ALCA, a qual, eliminando a tarifa comum de Mercosul, decorrentemente também eliminaria Mercosul. Por outro lado, para que os participes de Mercosul se aferrem na defesa e preservação deste é indispensável que resulte inequívoco, para cada um deles, que sair de Mercosul ou permitir a eliminação deste constitui uma opção muito pior do que a de permanecer em Mercosul e sustentar sua consolidação e expansão.

Em termos substantivos, há três questões fundamentais em jogo. A primeira consiste em se estudar as condições de que dependa a possível optimização do relacionamento argentino-brasileiro, no âmbito de Mercosul. A segunda consiste em se empreender um exercício semelhante, no tocante ao relacionamento do Paraguai e Uruguai com os dois sócios maiores. A terceira questão fundamental se relaciona com a ampliação de Mercosul, tanto no referente à formal incorporação, a este, dos três países sulamericanos qualificados para integrá-lo e propensos a fazê-lo Bolívia, Chile e Venezuela - quanto, de forma mais lata, no sentido de se ajustar, com o Pacto Andino, assim incluídos os países que não se tenham integrado em Mercosul, um acordo de livre comércio sulamericano. Acordo este que seria uma alternativa excludente de ALCA.

\section{Optimização possível}

A possível optimização do relacionamento Argentina-Brasil depende de uma objetiva e equiitativa análise dos fatores que inibem a capacidade exportadora da Argentina, tendo-se em vista, como objetivo final, lograrse um satisfatório equilíbrio no intercâmbio entre ambos os países e se adotar um regime que estimule "joint ventures" e investimentos em setores menos desenvolvidos, que se revistam, se modernizados, de perspectivas de competitividade.

No que se refere aos problemas tópicos, a matéria não comporta prescriçõe antecipadas, dependendo de cada caso. Importa, apenas, a necessidade, por parte do Brasil, de partir de uma posição de abertura que favoreça soluções positivas, ainda que o Brasil deva arcar, por certo prazo, com ônus que resultem de temporário favorecimento de alguns setores argentinos.

O problema mais grave, entretanto, é o que decorra da rigidez cambial argentina, fixando uma paridade que sobrevaloriza, em algo da ordem de $30 \%$, o peso argentino, assim severamente limitando sua capacidade exportadora. A dificuldade principal, no caso, decorre, como é sabido, do fato de que uma altíssima percentagem da dívida interna argentin está fixada em dólares, com a conseqüência de que uma realista desvalorização do peso se tornaria insuportável para os devedore domésticos. Ante a dupla inviabilidade de se conservar a atual paridade e de se desvalorizar peso, impõe-se a necessidade de uma solução extremamente engenhosa. É provável que a única solução possível seja a adoção pela Argentina ainda que temporariamente, de um regime de câmbio múltiplo. Manter, para transações financeiras, a paridade do peso com o dólar desvalorizar, real isticamente, o peso, para as transações de comércio exterior.
O relacionamento de Paraguai e Uruguai com os sócios maiores requer, ademais de outras providências, medidas que tomem ambos os países solidários com as exportações efetuadas pelos demais. Tal medida traria, adicionalmente, importantes beneficios para Argentina e Brasil. Entre as possíveis modalidades de se operacionalizar essa solidariedade, uma das mais práticas e, possivelmente, a mais vantajosa, consiste na criação de grandes "tradings" exportadores de Mercosul, de que sejam sócios, segundo um apropriado regime de proporcionalidade, os quatro (e futuramente os demais) membros de Mercosul. A criação de tais "tradings", adicionalmente à questão da solidariedade, é um imperativo para dinamizar a exportação por Mercosul, para o restante do mundo, de produtos de maior valor agregado. Esse sistema teria a vantagem de converter todo o território de Mercosul em uma grande plataforma comum de exportações, em que todos os participes teriam algo a ganhar com exportações procedentes do território de qualquer um deles.

A terceira importante questão em jogo, como precedentemente se mencionou, é a ampliação de Mercosul. Essa questão compreende dois distintos aspectos, um relacionado com a incorporação, a Mercosul, de países como Bolívia, Chile e Venezuela Outro consiste na adoção de um regime de livre comércio na América do Sul entre os países desse Mercosul ampliado e os remanescentes do Pacto Andino. Mercosul é o núcleo duro de um sistema econômico sul-americano. O regime de livre comércio, como alternativa excludente de ALCA, permitirá que países de capacidade econômica não excessivamente diferenciada se beneficiem da ampliação de seus mercador. Por outro lado, na medida em que satisfaçam os requisitos apropriados, os países que permaneçam no Pacto Andino poderão, se lhe interessar, ingressar futuramente em Mercosul. Este, a longo prazo, tenderá a englobar todos os países sul-americanos, integrando, com 
NAFTA e a U.E. o grupo dos grandes mercados regionais do mundo.

A constituição de uma área sulamericana de livre comércio, na forma precedentemente indicada, representa uma vantajosa alternativa ao projeto ALCA. Com efeito, este, colocando sob o mesmo regime de livre comércio a mais competitiva economia do mundo com as subcompetitivas economias do sul, forçaria estas a se reduzirem à produção de matérias primas e produtos de baixo valor agregado, enquanto as grandes multinacionais americanas ocupariam todo o espaço dos produtos e serviços de mais alta tecnologia. Diversamente, uma área sul-americana de livre comércio abriria os mercados da região à competição de empresas de semelhante níve de competitividade. Facilitaria, igualmente, observadas apropriadas medidas cautelatórias, um grande acordo de livre comércio com a União Européia, cujo nível médio de competitividade se aproxima, muito mais que o americano, do nível das empresas sul-americanas.

\section{Institucionalização}

O problema da conveniente institucionalização de Mercosul, precedentemente abordado, só parece comportar uma solução apropriada, na amplitude requerida para o caso mediante a ampliação de Mercosul. A agregação de Bolívia, Chile e Venezuela permitiria compensar o excessivo peso relativo do Brasil dentro do sistema, viabilizando a adoção de critérios de proporcionalidade, na formação dos órgãos supranacionais. A futura incorporação de outros países sul-americanos facilitaria, ainda mais, a questão da proporcionalidade. É certo que a ampliação do número de participes torna mais complexa a adoção de deliberações comuns. O caso da União Européia, entretanto, contando com o complicador de distintos idiomas, que a quase identidade portuguêsespanhol não apresenta, mostra como é possível, mediante apropriado regime institucional, operar um coletivo em relação ao qual o sistema sul-americano teria bem menor número de participantes.

\section{O Co-Seguro no Direito Brasileiro: Entre a Fragilidade da Prática e a Necessidade de Reconstrução Positiva do Instituto ${ }^{1}$}

\author{
Dra. Gudith Martins-Costa
}

Professora de Direito Civil na Faculdade de Direito da UFRGS;

Doutora em Direito na Universidade de São Paulo. Advogada

SUMÁRIO:

INTRODUÇÃO

I - As fragilidades da prática

A) O "paradoxo brasileiro": da inexistência de verdadeiro co-seguro;

B) As normas incidentes.

II - As conseqüências, para a prática, da inserção, no novo Código Civil brasileiro, de regra específica, e da incidência do Código de Defesa do Consumidor

A) $\mathrm{O}$ co-seguro frente às diretrizes fundamentais do novo Código;

B) Co-seguro e relação jurídica de consumo. Conclusão.

\section{Introdução}

O co-seguro constitui operação econômico-jurídica pela qual várias empresas de seguros, conjuntamente, e sem que entre elas haja solidariedade ${ }^{3}$, assumem determinado risco, mediante um contrato de seguro único ${ }^{4}$, com as mesmas garantias e período de duração e com um prêmio global. Assim afirma a legislação

estrangeira ${ }^{5}$, assim leciona a doutrina ${ }^{6}$, que 0 distingue claramente da hipótese de pluralidade de seguros e do resseguro, seja pelo critério das distintas finalidades desses institutos, seja pela análise da operação econômica subjacente, seja pelo exame da relação estabelecida entre as empresas seguradoras e a parte segurada.

Texto apresentado ao II Fórum de Direito Do Seguro "José Sollero Filho", promovido pelo IBDS, Instituto Brasileiro de Direito do Seguro, Porto Alegre, novembro de 2001. Agradeço ao Professor Doutor Paulo TOLEDO PIZA, I Vice -Presidente do Instituto Brasileiro de Direito do Seguro a disponibilidade e o profícuo "diálogo". Aos meus orientandos Tatiana de OLIVEIRA DRUCK, do Programa de Pos-Graduação - Mestrado e Felipe TEIXEIRA NETO, do Programa de Iniciação Cientifica, ambos da Faculdade de Direito da UFRGS, sou grata pelo auxílio na pesquisa

${ }_{3}^{3}$ Acerca da existência ou não de solidariedade em razão da prática brasileira do co-seguro veja-se, adiante, a segunda parte.

4 Sobre a unicidade do contrato veja-se MUNÕZ PAREDES, José Maria El coaseguro tradicional y la próctica contemporánea:cuestiones fundamentales del coaseguro moderno. Anais do II Forum de Direito do Seguro José Sollero Filho, Porto Alegre, novembro de 2001.

5 A definição ora posta funda-se na legislação portuguesa, DL 94-B/98, de 17 de abril, art. 132. Vejam-se as observaçōes de VASQUES, José, Contrato de Seguro, Coimbra, Coimbra Editora, 1999, p.51 e ss,com referências à legislação e doutrina européias.

VASQUES, José, Contrato de Seguro e MUNÕZ PAREDES, José Maria, El coaseguro tradicional y la práctica contemporánea:cuestiones fundamentales del coaseguro moderno, ambos já citados.

Revista da Faculdade de Direito da UFRGS, v. 21, Março/2002 